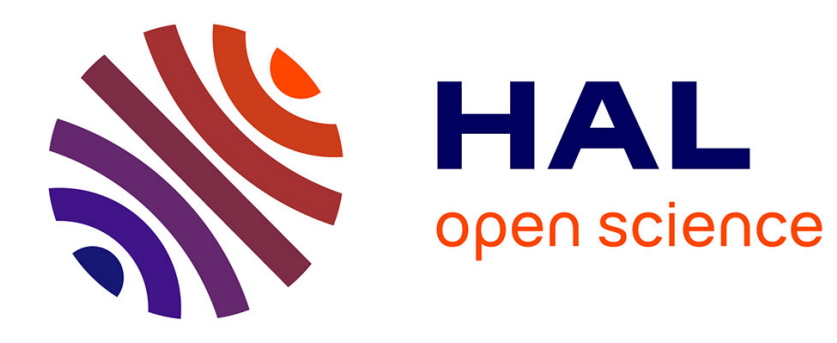

\title{
Derogatory Terms in Free Indirect Discourse
}

Isidora Stojanovic

\section{To cite this version:}

Isidora Stojanovic. Derogatory Terms in Free Indirect Discourse. The Language of Fiction 2021, pp.349-378, 2021. hal-03096106v2

\section{HAL Id: hal-03096106 \\ https://hal.science/hal-03096106v2}

Submitted on 7 Dec 2021

HAL is a multi-disciplinary open access archive for the deposit and dissemination of scientific research documents, whether they are published or not. The documents may come from teaching and research institutions in France or abroad, or from public or private research centers.
L'archive ouverte pluridisciplinaire HAL, est destinée au dépôt et à la diffusion de documents scientifiques de niveau recherche, publiés ou non, émanant des établissements d'enseignement et de recherche français ou étrangers, des laboratoires publics ou privés. 


\title{
Derogatory Terms in Free Indirect Discourse
}

\author{
Isidora Stojanovic \\ isidora.stojanovic@cnrs.fr \\ Author's draft of the chapter published in Maier, Emar and Stokke, Andreas (Eds.), The Language of Fiction, \\ Oxford University Press 2021, pp. 349-378
}

\begin{abstract}
Free indirect discourse (FID) is a style of reporting speech and thought that combines thirdpersonal narration with direct, first-personal discourse. Expressive terms, such as "idiot" or "asshole", are known to occur in FID. When so used, the pejorative content reflects the protagonist's rather than the narrator's point of view. This chapter broadens the discussion of derogatory terms in FID by investigating occurrences of slurring terms, such as the N-word. The two main approaches to FID, namely, the two-context approach and the mixed-quotation approach, are discussed in light of these novel findings. The chapter shows that both are able to account for the data; however, the choice between them imposes constraints on the underlying theory of derogatory terms.
\end{abstract}

\section{Keywords}

expressive terms; pejoratives; slurring terms; the N-word; point of view; context; quotation

\section{Warning}

This chapter cites examples that contain offensive vocabulary. We apologize for any offense caused.

\section{Introduction}

There are two well-known ways of reporting speech and thought: direct discourse (henceforth DD) and indirect discourse (henceforth ID), illustrated in (1) and (2):

(1) Suleiman said/thought: "I will do it tomorrow".

(2) Suleiman said/thought that he would do it on the next day.

In narrative, however, there is yet a third, often preferred way: free indirect discourse (henceforth FID), illustrated in (3):

(3) The garden needed watering, but Suleiman was tired. He would do it tomorrow. 
FID has features in common with both DD and ID. As in ID, certain referential devices such as pronouns and tenses require readjustment. Both in (2) and (3), the first person pronoun "I" from Suleiman's original utterance or thought is converted into the third person pronoun "he", and the future tense "will do" takes on the past form "would do". As in DD, on the other hand, other expressions, such as "tomorrow", are preserved. When we read (3), we understand that Suleiman said/thought that he would water the garden on the day after his speech or thought took place, rather than the day after the narration in (3) takes place. In FID, indexicals such as "tomorrow" pick out their referent from the perspective of the person whose speech or thought is being reported, rather than the reporter's.

While a large amount of the literature on FID has focused on the behavior of context-sensitive expressions such as "tomorrow", another remarkable feature of FID is that it features a range of expressions and constructions that are preserved, if at all, in DD, but not in ID: expressive elements such as "damn", "fucking", "idiot" or "asshole", various discourse particles (particularly well-evidenced for German: see Eckardt 2012), question- and exclamation marks, nonstandard pronunciation and dialect (indicated by different spelling), as well as disfluencies and pauses (indicated by typography).

This paper focuses on a subclass of expressive terms, namely, those that carry derogatory content. More specifically, we will be interested in two types of expressions, the difference between which will be clarified in section 2: pejoratives, such as "asshole" or "idiot", and slurs, such as the N-word. While the presence of the former in FID has often been noted, the latter have seldom been discussed in relation to FID, or even to fiction writing. This is surprising, given that the philosophical literature on slurs has grown exponentially since the beginning of the century. Our goal is to examine how the cases of derogatory terms in FID impact the scope and the plausibility the existing accounts of FID.

\section{Pejoratives in Free Indirect Discourse}

Derogatory terms are those that carry derogatory content, and are characterized by the fact that in using them, the speakers typically express their negative attitudes, such as hatred, contempt, derision or condescendence, toward the persons designated by the expressions at stake. There are two main classes of derogatory terms. The first consists of nouns such as "jerk" and "asshole", for which the derogatory content targets the individuals alone for whom the noun is used; we will be calling those pejoratives. ${ }^{1}$ The second consists of nouns such as "frog", when it is used as a

1 There is a lack of consensus regarding terminology. Both "pejoratives" and "epithets" are sometimes used for the broader class of derogatory terms that encompasses slurs. 
derogatory term for the French. What is special about such terms is that the derogatory content targets not only the individual to whom the noun is applied on a given occasion, but the entire group to which the individual belongs (as, in the case of "frog", all French people); we will be calling those slurs. There is considerable variation among slurs. One scale of variation is the degree of perceived offensiveness. "Frog", for instance, is derogatory, but not shockingly so; hardly any reader will feel particularly offended that this word is mentioned. On the other hand, the offensiveness of the $\mathrm{N}$-word is so strong that its mere evocation may already upset certain readers. Another scale of variation is the type of the target group. It can be race, ethnicity, gender, religion, sexual or political orientation. There is a range of terms for which it may not be straightforward whether they are pejoratives or slurs. Terms such as "bitch" and "slut" are a case at point: they may be seen as pejoratives that merely express the speaker's negative attitude toward the individual at stake, but at other times, they behave like slurs in that they express a derogatory attitude toward all women as such. ${ }^{2}$ There are also derogatory terms, such as "shithole", that are neither pejoratives nor slurs. ${ }^{3}$ While acknowledging the diversity and richness of derogatory vocabulary, this chapter will focus on some fairly paradigmatic examples of pejoratives and slurs.

It has often been noted that FID is prone to containing occurrences of expressives such as "damn", "fucking" or "idiot". Let me borrow an example from the literature, used by Emar Maier to substantiate the claim that "in free indirect discourse we find so-called speaker-oriented terms that are not clearly indexical, and that can occur in both direct and indirect discourse, but whose interpretation is as in direct discourse: i.e. relative to the reported speaker/thinker" (2014: 352):

(Example 1)

Samantha Puckett stood in the convenience store, glaring at the condoms that she had bought no less than two months and a week prior. Today was supposed to be the last day of her period. She was supposed to be pissed off that the disgusting fluids were still oozing from her body and ruining her life, but instead, she was looking at the supposed contraception that obviously didn't work since she was standing here looking like a fucking idiot. [...] She let out a sigh. Who the hell was she kidding? She was a good liar,

\footnotetext{
${ }^{2}$ See Ashwell (2016) for an insightful discussion of gendered slurs. See also Diaz-Legaspe (2019) for a proposal on how to delineate slurs from other pejoratives.

${ }^{3}$ Sennet and Copp (2019) argue that there is no unified class of derogatory terms; they give examples of derogatory verbs. Even within the same syntactic category (say, of nouns) there is considerable diversity; see e.g. Jeshion (2013, 2018) and Nunberg (2018) for discussion. See also Bolinger (2017) for a characterization of slurs.
} 
but she couldn't fool herself. She had all the typical symptoms. No period, sore tits and today she started puking all over the damn place like a drunk after a bar fight. ${ }^{4}$

The quoted passage illustrates FID perfectly: we have two occurrences of "today" that are used to refer to the day at which the narrated events took place, rather than the day of narration; we have question marks, colloquial language ("pissed off"), and, most interestingly for our purposes, expressive terms such as "fucking idiot" and "damn".

In the remainder of this section, we will provide more examples of pejoratives in FID in fictional narratives, and then discuss certain related uses of pejoratives, in which the derogatory content of the pejorative is interpreted from a perspective different from the speaker's or the narrator's.

\subsection{Corpus-drawn examples of pejoratives in FID}

Narratives abound with examples of free indirect discourse in which terms like "idiot" or "jerk" occur. However, what we typically see is the pejorative occurring inside an indefinite description that has been predicated of someone, as in "He was a jerk, (she thought)". Even in (Example 1), "idiot" occurs in the complex phrase "looking like a fucking idiot". Such predicative uses of pejoratives have been largely ignored by the literature on expressives, which has always focused on their referential uses, as in "that bastard Kaplan" (Kaplan 1999, Macià 2002, Potts 2005, 2007b, Schlenker 2007, Tonhauser et al. 2013). One reason for this is that the theoretical interest in expressives has been largely driven by issues regarding their projective behavior. ${ }^{5}$ Yet it is far from obvious whether predicating of somebody that they are an idiot or a jerk has any projective content. 6 While the paradigmatic examples of pejoratives discussed in the literature on expressives are constructions such as "that fucking idiot", somewhat disappointingly, we have not found many corpus-drawn examples of such terms occurring in FID. Nevertheless, here are two examples featuring "asshole" in FID, to be further discussed in later sections:

\section{(Example 2)}

After the anesthetic wore off, Tom made a deal with the patrol. He'd get them their trophy, just not today. He had too much money riding on this whale. Give him a week, and he'd give them their prize. Patrols were easy to bribe that way. It was too bad,

\footnotetext{
${ }^{4}$ www.fanfiction.net/s/7474039/1/iKnocked_Up

5 Roughly speaking, a content "projects" when it is not affected by the meaning of operators or similar constructions that embed it. Presuppositions and conventional implicatures are paradigmatic examples of projective content; for discussion, see e.g. Simons et al. (2010).

6 In Cepollaro, Domaneschi and Stojanovic (2020), we show that even on their predicative uses, pejoratives impose certain interesting constraints on the context.
} 
though, because Tom'd taken a real dislike to the asshole. Jake, on the other hand, seemed like a pretty decent guy. (Vladimirsky 2014: p. 14)

(Example 3)

Her chest tightened. She was resilient, often unflappable, used to things not going her way, practiced at gathering herself in trouble or after failure. If he were to appear beside her on this deck, she'd slug him. The asshole. Who would make her laugh now? How could he have left her alone? She considered the dark water churned into a white froth by the ship's passage. (Lee 2015)

In Example 2, we see a first clear illustration of FID in the second sentence: the indexical "today" is interpreted from the perspective of the protagonist Tom, yet reference to Tom and to the relevant episode is made from the perspective of the narrator. And when we get further down to "the asshole", we understand that the designated person is held in low opinion by Tom, rather than the narrator.

In Example 3, the verbless sentence "The asshole" clearly reflects the perspective of the woman standing on the deck. Further clear cues of FID are present: the proximal demonstrative "on this deck" (rather than "on that deck"), the indexical "now", as well as the question marks.

\subsection{Broadening the spectrum of shifted uses of pejoratives}

Examples 2 and 3 are uncontroversial instances of FID. In both, the narrator is reporting a speech or thought episode of the protagonist. Example 2 starts as a report of what Tom presumably told the patrol, and turns into what he further thought. In Example 3, the FID reports the woman's reflections while she was standing on the deck and contemplating the dark water.

Interestingly, we also find examples of pejoratives and, more generally, expressives in narrative that reflect the protagonist's perspective, even though no thought or speech appears to be plausibly reported. Consider:

\section{(Example 4)}

And he felt it then again, years later, when a teenage Khaleesi got into a car accident, and the idiot father of the idiot boy she'd been with couldn't remember the name of the hospital they'd been taken to, and Tony spent ten panicked minutes dialing hospitals around La Jolla and San Diego before the asshole called back with the information. (Markeley 2017: p. 199)

\section{(Example 5)}

Ce pauvre diable d'ouvrier, perdu sur les routes, l'intéressait. ("This poor devil of a 
worker, wandering and on the road, interested him") (Zola 1930; cited in Banfield 1982 p.202, and in Abrusán 2020 p. 7)

In Example 4, "the idiot father", "the idiot boy" and "the asshole" all reflect the negative feelings that the protagonist, Tony, had toward Khaleesi's boyfriend and his father. Nevertheless, there is no proper thought or speech that is being reported, which is the primary function of FID. Similarly, in Example 5, "pauvre diable" ("poor devil") is a somewhat quaint pejorative that reflects the condescending attitude of the protagonist, rather than the narrator, toward the worker; nevertheless, no thought- or speech-reporting is at stake. Examples such as these, akin to FID in that they involve a certain shift in perspective, are attributed to what is mostly known as Protagonist Projection (see Stokke 2013, Hinterwimmer 2017, Abrusán 2020).7

Further examples that feature referentially used pejoratives whose derogatory content is attributed to some salient protagonist, rather than the speaker or the narrator, can be found in the experimental work of Harris and Potts (2009) and Kaiser (2015). ${ }^{8}$ The impetus for the experimental studies in Harris and Potts (2009) derives from a series of observations from Amaral et al. (2007), who offer counterexamples to Potts (2005)'s prediction that pejoratives (as well as appositives) are always speaker-oriented, whether embedded or not. Harris and Potts (2009) are specifically interested in the availability of non-speaker-oriented readings for unembedded occurrences. For the case of pejoratives, they ran an experimental study, in which they presented the participants with two-sentence sequences, where the first sentence varied across four conditions, and the second contained a pejorative occurring in an anaphoric definite description (such as "the jerk"). ${ }^{9}$ Here is a sample item:

Suppose you and I are talking and I say:

A. My classmate Sheila said that her history professor gave her a low grade.

(Negative, N)

B. My classmate Sheila said that her history professor gave her a really low grade.

\footnotetext{
7 Banfield (1982) attributes Example 4 to a phenomenon of "non-reflective consciousness", while Hinterwimmer (2017) talks of "perspective shift". See also Stokke (this volume) on "character focus". On the differences between FID and protagonist projection, see Abrusán 2020.

8 Harris and Potts (2009) were equally interested in non-speaker-oriented uses of appositives, for which they pointed to the corpus data in Potts and Harris (2009); unfortunately, there is no similar appeal to corpus data for pejoratives. For further experimental work on perspective-shifting, see Bimpikou (2020); her experimental stimuli, however, do not include epithets.

9 Harris and Potts (2009) are interested in non-speaker-oriented uses of both appositives and pejoratives; for the former, they point to corpus data drawn from the corpus of Potts and Harris (2009); unfortunately, there is no similar appeal to corpus data for the latter. For further experimental work on perspective-shifting, see Bimpikou (2020); her experimental stimuli, however, do not include epithets.
} 
(Negative, Y)

C. My classmate Sheila said that her history professor gave her a high grade.

(Positive, N)

D. My classmate Sheila said that her history professor gave her a really high grade.

(Positive, Y)

Target sentence: The jerk always favors long papers.

The participants were then asked "Whose view is it that the professor is a jerk?" and had a multiple choice: "Mine (Speaker); Sheila’s (Subject); Mine and Sheila's." The following table sums up the results:

$\begin{array}{llll} & \text { Subject } & \text { Speaker } & \text { Both } \\ \text { Positive } & \mathbf{7 \%} & \mathbf{8 8 \%} & \mathbf{5 \%} \\ \text { (Positive N } & 3 \% & 45 \% & 1 \% \text { ) } \\ \text { (Positive Y } & 4 \% & 43 \% & 4 \% \text { ) } \\ \text { Negative } & \mathbf{1 7 \%} & \mathbf{5 4 \%} & \mathbf{2 9 \%} \\ \text { (Negative N } & 7 \% & 29 \% & 15 \% \text { ) } \\ \text { (Negative Y } & 10 \% & 25 \% & 14 \% \text { ) }\end{array}$

Based on these results, Harris and Potts concluded: "speaker-oriented interpretations were preferred across conditions. However, while $88 \%$ of the judgments for the Positive condition were speaker-oriented, just 55\% were speaker-oriented in the Negative condition" (p. 18) and concede that "non-speaker-oriented readings are possible for expressives, if the right contextual factors are present" and that "such readings do not require syntactic embedding" (p. 20).

It is not surprising that the speaker-oriented interpretation would be preferred in the Positive condition, for the first sentence provides a context that suggests that the reportee (what Harris and Potts call "subject") should have a positive opinion of the referent, which clashes with the negative content associated with the pejorative. On the other hand, one might wonder why that would be the preferred interpretation in the Negative condition. There is, however, an explanation for this. As Kaiser (2015: 350) points out, "when looking at the structure of their experimental stimuli, it is worth noting that all of the 16 epithet items (...) included an explicit linguistic realization/mention of the speaker, most often in the form of a possessive pronoun on the subject, e.g., my sister Trudy, my friend Mike, my aunt" or, as in the example cited above, my classmate Sheila.

Kaiser conducted a first follow-up study, consisting of two experiments: one was a nearreplication of Harris \& Potts (2009), while the other had the wording of the items adjusted in such a way that the speaker was less linguistically salient (e.g. replacing "my classmate Sheila" 
simply by "Sheila"). Nevertheless, even in the less-salient condition, the speaker-oriented interpretation was still the preferred one. But more relevant to our purposes are her next two studies, which consisted of two-sentence sequences that varied across two conditions, depending on whether the second sentence included or not a pejorative or an evaluative term. ${ }^{10}$ Here are two sample stimuli:

a. Mary looked woefully at Elizabeth. She was sick. [regular sentence]

b. Mary looked woefully at Elizabeth. Poor girl; she was sick. [FID cue]

a. Arthur hollered at Eric at the restaurant. He didn't care about using foul language in a room full of people. [regular sentence]

b. Arthur hollered at Eric at the restaurant. That ignorant jerk; he didn't care about using foul language in a room full of people. [FID cue]

Participants were then asked "Who was sick?", or "Who didn't care about using foul language?", and were given a six point scale ranging from "Definitely Mary" to "Definitely Elizabeth". The underlying reasoning for the choice of this task was the following:

A key property of our stimuli is that the first sentence contains two third-person referents with the same gender (...), and the second sentence contains a potentially ambiguous third person pronoun (he/she). The stimuli were designed so that in the plain/non-cued version (a), the pronoun is fairly ambiguous: It could refer to the preceding subject or object/oblique argument, perhaps with a slight bias for the subject. However, in the cued versions (b), if readers recognize a perspective shift to FID and the POV of the subject character, this should lead them to interpret the pronoun as referring to the preceding object. (Kaiser 2015: 362)

The results confirmed the prediction. As Kaiser writes: "Participants are more likely to interpret the pronoun as referring to the preceding object (a sign of them having shifted to the perspective of the preceding subject) in the presence of epithet/evaluative expressions. (...) This suggests that participants are indeed sensitive to the perspective shift triggered by FID cues" (ibid., 365).

To forestall a possible misunderstanding, these two studies did not aim to test directly whether pejoratives in FID reflect the protagonist rather than the narrator's perspective. Rather, the presence of pejoratives (and evaluative terms) meant to serve as a cue for FID, which, in turn,

10 Kaiser (2015) also tested the availability of non-speaker-oriented readings for epistemic adverbs such as "probably", but those are not relevant to our present purposes. 
favored the interpretation of a potentially ambiguous pronoun from the shifted perspective. ${ }^{11}$ Nevertheless, the stimuli of the studies may still be taken to provide empirical evidence to the effect that (unembedded) pejoratives may reflect the point of view of a salient protagonist, rather than the speaker or the narrator.

\section{Slurs in Free Indirect Discourse}

Slurs have a strong expressive component. In using them, the speakers express their hatred, contempt, or other negative attitudes toward not only the persons for whom the slur is used on a given occasion, but toward the entire group to which they belong. If a speaker uses the N-word to refer to somebody, they are not only offending that person in the way they would if they were to use a pejorative such as "asshole"; they are expressing a plethora of racist prejudice, thereby harming billion people.

Given that slurs are so strongly expressive, and that FID likes to preserve expressive elements of all sorts, one should, in principle, expect to see occurrences of slurs in FID. In principle, because the offensive and derogatory character of slurs could be so strong as to overthrow a writer's desire for the use of such expressive vocabulary in FID. This section shows that the initial expectation is borne out: we do encounter slurs in FID. However, before we take a look at those, we need to disentangle certain notions that we have been taking for granted so far.

\subsection{Protagonists, narrators and authors}

Following the literature on FID, the contrast in which we have been mainly interested is between the narrator and the protagonist, or relatedly, between the context of the narrating event and the context of the reported (thought- or speech) event. We have neglected the contrast between the narrator and the author (or, if you prefer, the writer). In certain narratives, the contrast is neat. Mark Twain's The Adventures of Huckleberry Finn is written, of course, by Mark Twain, but the events are narrated by Huckleberry Finn, in a first person mode. Similarly, Lee Harper's To Kill $a$ Mockingbird is written by Lee Harper but narrated by Scout Finch. In both novels, it is easy to identify the narrator through the persistent use of first person pronoun. And in both, the narrator is also one of the novel's protagonists. But there are other narratives, written in a third person mode, in which the reader does not know, and need not know, who the narrator is. In many, possibly the majority of novels, the events are narrated from what seems to be an impersonal stance, from an over-arching, omniscient point of view. For such narratives, one may be tempted

11 I am grateful to Emar Maier for pressing this point. Relatedly, Abrusán (this volume, p. 19) refers to Kaiser (2015) as providing evidence that epithets (that is, pejoratives) serve as FID-cues. 
to say that the narrator just is the author. However, as Genette writes, "(...) in a more subtle and also more radical way, the narrator of Père Goriot "is" not Balzac, even if here and there he expresses Balzac's opinions, for this author-narrator is someone who "knows" the Vauquer boardinghouse, its landlady and its lodgers, whereas all Balzac himself does is imagine them; and in this sense, of course, the narrating situation of a fictional account is never reduced to its situation of writing" (1972/1980, p. 214).

When we look at FID, it is customary to assume that each element is interpreted with respect to either the narrator's or the protagonist's context; the writer's context is normally irrelevant. But slurs, because of their highly offensive derogatory character, appear to engage the writer in ways in which pejoratives do not. A word like "asshole" derogates only the person to whom it is applied, and it would be weird for a writer to use it in order to express their negative feelings toward some fictional character. ${ }^{12}$ However, slurs bring in a further dimension of insult. A writer who decides to use a slurring term may be plausibly taken to thereby express their contempt for the relevant social group. The derogatory attitude is naturally ascribed to the writer especially in those cases in which there is no prominent narrator, or in which the events are narrated from an impersonal point of view. But even when there is a clear narrator figure, as in first-personal narrative, this need not by itself impede that the derogatory stance be ascribed to the writer. A famous case is the controversy surrounding Mark Twain's The Adventures of Huckleberry Finn ever since it was published. The novel contains over 200 occurrences of the N-word, and even though they come, so to speak, out of the mouth of Huck Finn, accusations of racism have often been voiced against Mark Twain himself. ${ }^{13}$

To bring the point home, slurring language in narrative brings along a whole myriad of further complexities that fall beyond the aim of the present chapter. In what follows, our focus will be on FID and the narrator-protagonist contrast. The next section provides corpus-drawn examples in which the derogatory content of slurs in FID reflects the protagonist's point of view. Whether some of that content also projects to the narrator or, as the case may be, to the author, is a further issue that we will not address.

\footnotetext{
12 Admittedly, things may get more complicated in fictional narratives that involve real people.

${ }^{13}$ Even just recently, there has been a new edition of the novel in which the $\mathrm{N}$-word was systematically replaced by "slave"; see https://www.theguardian.com/books/booksblog/2011/jan/05/censoring-mark-twain-n-wordunacceptable. While it is uncontroversial among the Twain scholars that he was not racist and that, to the contrary, his repeated use of the $\mathrm{N}$-word was deliberate in the aim of conveying an anti-racist message, many ordinary reader take the derogatory content to project beyond the narrator's context, into the writer's and even the reader's context (see also section 4.3.1.). For an interesting analysis of the role of the N-word in Twain's novel, see Sloane (2014).
} 


\subsection{Corpus-drawn examples of slurs in FID}

Our first example has been taken from Harper Lee's classic To Kill a Mockingbird:

\section{(Example 5)}

Maycomb was interested by the news of Tom's death for perhaps two days; two days was enough for the information to spread through the county. "Did you hear about?... No? Well, they say he was runnin' fit to beat lightnin'..." To Maycomb, Tom's death was typical. Typical of a nigger to cut and run. Typical of a nigger's mentality to have no plan, no thought for the future, just run blind first chance he saw. Funny thing, Atticus Finch might've got him off scot free, but wait—? Hell no. You know how they are. Easy come, easy go. Just shows you, that Robinson boy was legally married, they say he kept himself clean, went to church and all that, but when it comes down to the line the veneer's mighty thin. Nigger always comes out in 'em. (Lee 1960, p. 244)

To help situate the passage, the events are taking place in Maycomb, a small town in Alabama, in the early 1930s. Tom Robinson had been accused for a rape that he didn't commit. Although Atticus Finch, his lawyer (and the father of Scout, who is narrating the events) had a good chance of having him declared not guilty on appeal, Tom tries to run away from prison and gets shot.

There are several things to note about this passage. First, while the protagonist whose point of view is relevant for the interpretation of FID is typically some character from a novel or story, here, we have a collective agent, namely, the entire community of Maycomb. Second, FID is smoothly introduced by setting the stage with a piece of DD, followed by a phrase that makes the relevant perspective explicit, namely "to Maycomb." Constructions characteristic of FID appear throughout the passage, such as question marks and expressive elements like "Hell no." Also, Harper Lee carefully chooses to end the last sentence with the shortened form " 'em", instead of "them", thereby making it clear that we are still inside FID, and that the relevant perspective into which the N-concept is anchored is Maycomb's, not the narrator's.

We will return to a discussion of how best to understand the behavior of slurs in FID in the next section. Before that, let us enrich our object of inquiry with more examples. The second one is more contemporary:

(Example 6)

Now the boys were approaching the dead man, warily. They were joking and snickering out of fear. An unemployed psychologist, Jack understood this; he knew better than to be angry. One of the boys put out his sneakered foot and prodded at the man's arm, which was flung out at an impossible angle, and now another boy reached down and yanked at 
his shoulder. Each time they backed away, laughing, but then came a bit closer on their next approach. Vultures, Jack thought. Damn nigger vultures. But he chided himself for this thought. Very often had Jack told his colleagues and friends and his ex-fiancee, Mara, that he didn't mind living this close to downtown, that he didn't feel threatened as a white man living in this run-down area whose streets were overrun by drug dealers and prostitutes and stray restless gangs. (Johnson 1996, p. 1)

In this passage, the slur under consideration appears in a sentence that comes right after a belief report in which a parenthetical "he thought" appears. The slur is preceded by "damn", which emphasizes its expressive nature. What is also noteworthy is that the strong derogatory content that the slur encodes appears to be a substantive elements of Jack's reported thought; for this is why he chided himself for it, as the remainder of the passage explains. To be sure, one could debate whether the relevant passage, namely "Vultures. Damn nigger vultures" is really FID as opposed to DD (or even ID). True enough, the passage does not occur within quotation marks; but one could argue that quotation marks, albeit a conventional mark of DD, are not strictly necessary. We are happy to grant that the example could be analyzed as DD, but could also be plausibly seen as FID. ${ }^{14}$

Our third example containing the N-word comes from William Faulkner's The Light in August:

(Example 7)

There was nothing in his eyes at all, no pain, no surprise. But apparently he could not move; he just lay there with a profoundly contemplative expression, looking quietly up at the two men, and the blonde woman still as immobile and completely finished and surfaced as a cast statue. Perhaps he could not hear the voices either, or perhaps he did and they once more had no more significance than the dry buzzing of the steady insects beyond the window:

Bitching up as sweet a little setup as I could have wanted.

He ought to stay away from bitches.

He can't help himself. He was born too close to one.

Is he really a nigger? He don't look like one.

(Faulkner 1932, p. 89)

While throughout Faulkner's novel the N-word appears very often (at a frequency greater than once every two pages), only three times does it appear outside quotation marks: here, in another passage that may be seen as FID and in which it occurs similarly in italics, and once in ID (see

14 The observation that Example 6 could be simply DD comes from Emar Maier; perhpas unsurprisingly, since, as we shall see, Maier's mixed-quotation account aims to assimilate all FID to DD. 
Example 9). The part in italics reflects something like the protagonist's inner discourse. It is interesting to observe that it begins as DD, preserving the first person pronoun "I", but then flows smoothly into FID: the reported thoughts are still the protagonist's first-personal thoughts, but the narrator now uses the third person pronoun "he".15

To help understand what is going on in this passage, the protagonist is Joe Christmas, a man whose mother dies at childbirth, whose father is unknown, and who grew up with religious adoptive parents against whom he rebels. Faulkner's novel is often described as being about the search of one's identity, and in Joe's case, racial identity appears to be a central component. What is striking here is that it is not quite clear to whose perspective the derogatory, racist content associated with the $\mathrm{N}$-word is attributed. Christmas himself, although raised in a racist environment, does not necessarily endorse this perspective. When he wonders about his racial identity, it is unclear whether he has any corresponding derogatory attitudes. Rather, when he deploys the $\mathrm{N}$-concept, it is as if he echoed the way in which others see him. ${ }^{16}$

Let us end this section with one more example:

\section{(Example 8)}

Of course, Art could have sued over this incident if he could have proved that it had happened. Some people, most notably Lisa, thought he certainly ought to have at least quit. But he didn't sue and he didn't quit. He took his tennis racket on the nose, so to speak, and when the next day his boss apologized for losing control, Art said he understood. And when his boss said that Art shouldn't take what he said personally, in fact he knew Art was not a Jap, but a chink, plus he had called someone else a lazy wop just that morning, it was just his style, Art said again that he understood.

(Jen 1994, p. 17)

15 The switch to the third person pronoun is the main indicator that we are switching from DD to FID. Note, however, that the other hallmark of FID, namely, the readjustment of tenses, is still missing here.

16 It may be helpful to provide the text that precedes the quoted passage:

"Perhaps Joe did not hear her at all, nor the screaming waitress: "He told me himself he was a nigger! The son of a bitch. Me f-ing for nothing a nigger son of a bitch that would get me in a jam with clodhopper police. At a clodhopper dance!" Perhaps he heard only the long wind, as, swinging his hand as though it still clutched the chair, he sprang over the two men. Perhaps he did not feel either blow, though the stranger struck him twice in the face before he reached the floor, where like the man whom he had struck down, he lay upon his back, quite still. But he was not out because his eyes were still open, looking quietly up at them." (Faulkner 1932, p. 89)

When we get to the occurrence of the N-word in FID, it may be plausible to see it as directly echoing the very words that the woman employed in regard to Joe Christmas. Note en passant that the text uses "f-ing" instead of the full form, treating "fuck" as a taboo word, while the much more offensive slur gets fully spelled out. 
This example involves a mixture of ID and FID. Some might even argue that the entire text that comes after "when his boss said that", including the sentences in which the slurs occur, are bona fide embedded under "that" and, therefore, part of ID. But then, one could reply that the use of the slurs is precisely an indicator that we have FID. Just as Examples 6 and 7 show that the boundary between DD and FID can be shaky, Example 8 shows that the boundary between FID and ID can also be; we shall return to this example in section 4.3.2.

\section{Discussion}

Let us take stock. We started by presenting, in Section 1, certain features that are characteristic of FID. In a nutshell, in FID, expressives as well as (most) indexicals are typically anchored to the protagonist's rather than the narrator's perspective, while pronouns and tenses behave the other way round. ${ }^{17}$ In Section 2, we presented empirical evidence, drawing on examples from fictional narratives as well as on experimental studies, to the effect that pejoratives such as "jerk" and "asshole" in FID reflect the protagonist's rather than the narrator's perspective. In Section 3, we turned our attention to slurs. We presented examples of slurs in FID that appear to be anchored to the protagonist's rather than the narrator's perspective. The goal of this last section is to see how the data presented in Sections 2 and 3 fit into our best theories of FID, on the one hand, and of pejoratives and slurs, on the other. In Section 4.1., we will give a rough outline of the two main approaches to FID: the two-context approach and the mixed-quotation approach. In Sections 4.2. and 4.3., we will see how the two approaches can handle, respectively, pejoratives and slurs, as they occur in FID.

\subsection{The two-context approach and the mixed-quotation approach}

It is fair to say that the mainstream approach to FID is the two-context approach. This approach actually covers a family of different accounts, the differences among which are not particularly relevant for the present purposes. The main idea is that the interpretation of FID requires relativization to two contexts: one, namely that of the narrator, and another, namely that of the protagonist whose speech or thought are being reported. This idea is already present in Banfield (1973, 1982), but, to our knowledge, it is not until Doron (1991) that the idea was cast in a more rigorous semantic setting. Doron's discussion is set against the background of Kaplan (1989),

\footnotetext{
17 In fact, the matter is more complicated, since the interpretation of gender features associated with pronouns can take the protagonist's rather than the narrator's perspective; see Doron (1991), Schlenker (2004), Sharvit (2008) and Maier (2015) for discussion.
} 
which, by that time, ${ }^{18}$ had been established as the dominant approach to indexicality and contextdependence. The gist of Kaplan's proposal is that semantic interpretation requires two parameters: a context, which allows us to interpret indexicals, and a circumstance of evaluation, which tells us what is and what is not the case (at a given time). Thus if Suleiman says on 15 June 2019 "I graduated yesterday", the content expressed by his utterance is that Suleiman graduated on 14 June 2019; but to determine the truth value of Suleiman's utterance, we need to evaluate this content relative to the relevant circumstances of evaluation. Thus with respect to a possible world in which he did graduate on that day, his utterance is true, but with respect to a different possible world in which he never graduated, or did so on a different day, his utterance is false. In Kaplan's view, all indexicals are interpreted with respect to the context of utterance; furthermore, they are "unshiftable", in the sense that there are no linguistic expressions or constructions, other than quotation, that mandate interpreting the indexical in a different, "shifted" context. 19

Doron opens her article by showing that FID poses a problem for Kaplan's proposal. For, as we saw in the introduction, in FID, some context-sensitive expressions, namely tenses and pronouns (at least with respect to person features) are interpreted relative to the context of the narration (which would be the context of utterance), but other expressions, including temporal indexicals like "tomorrow", locational adverbs like "here", and demonstratives like "this", are interpreted relative to the protagonist's context. Doron's proposal is that in addition to the two parameters distinguished by Kaplan, we need to relativize interpretation to yet a third parameter. As she puts it: "In order to account for FID, I therefore propose to relativize meaning not only to the discourse but also to the point of view, which represents the focus of consciousness" (Doron 1991: 57). Here, "discourse" is short for "discourse situation", which would correspond to a Kaplanian context. ${ }^{20}$ She continues: "First and second person pronouns, for example, are discourse-situation sensitive but point-of-view insensitive. (...) Demonstratives, unlike first and second person pronouns, for example, are point-of-view sensitive but discourse-situation

\footnotetext{
18 While Kaplan's manuscript "On Demonstratives" was published only in 1989, it had been widely circulated since the early 1970 's.

19 The idea that there are no constructions other than quotation that can lead to interpreting an indexical in a shifted context is known as the ban on, or prohibition against, monsters; "monster" being Kaplan's term for operators that shift the context. Kaplan's view has been challenged on a number of occasions, one of the most influential of which is Schlenker (2003), who appeals to cross-linguistic data to show that there are shiftable indexicals. For more recent discussions, see Maier (2016), Deal (2017), Stojanovic (2020: sect. 5.3.), and the references therein.
}

20 In her formal proposal, Doron uses elements from the situation theory of Barwise and Perry (1983), but the proposal itself does not really depend on adopting that framework. What matters is that we have two context-like parameters, and that some context-sensitive elements are interpreted relative to one while others are interpreted relative to the other. 
insensitive. (...) Third person pronouns are sensitive to both discourse and point of view" (ibid: 58-59).

This idea that the semantics of FID requires relativization to two context parameters, namely, the context of the reported thought/speech and the context of narration, has been endorsed by several subsequent accounts of FID, including Schlenker (2004), Sharvit (2008), Eckardt $(2012,2015)$ and Abrusán (2020). The accounts differ on how they incorporate the two-context idea into semantics. For Sharvit (2008), those elements that are interpreted with respect to the protagonist's context are embedded under a covert context-shifting operator, as if there were a hidden attitude- or speech-reporting verb such as "said/thought". It is, then, the interpretation of this covert operator that introduces the second context. For Schlenker, the two contexts are postulated in the semantic machinery, and the lexical clauses of the different lexical items indicate with respect to which of the two contexts the item is to be interpreted. Taking $v$ to stand for the context of utterance and $\theta$ for the context of thought (to use Schlenker's own terminology), the idea is that all sentences are interpreted with respect to both $v$ and $\theta$, but while pronouns and tenses receive their semantic values from $v$, all the other indexical elements receive them from $\theta$. For Eckardt (2015), the two contexts are similarly available from the outset, but the appeal to the second, protagonist's context is optional. However, whenever that happens, all the context-sensitive elements except pronouns and tenses receive their semantic values from that context, rather than the context of narration. Abrusán (2020) endorses Eckardt's framework and extends it to account for protagonist projection (see section 2.2.).

The two-context approach stresses the analogies between FID and ID, as is particularly clear in Sharvit's proposal, given that she appeals to covert ID-like operators. Maier (2015) offers a different take on FID, one that stresses the analogies between FID and DD. The gist of his proposal is that although quotation marks may not be visible, the text or discourse in FID is quoted, while certain elements, such as pronouns and tenses, may be un-quoted. Maier's account draws on certain ideas from Shan $(2007,2011)$, the technical details of which need not concern us here. What matters to our purposes is that FID is, at the bottom, DD; the difference is that certain elements are pulled out, so to speak, of the quoted material, and adjusted to the narrator's context. Something similar happens, Maier suggests, in many ordinary examples of (mixed) quotation, where one would use the typological convention of brackets to indicate that a given item is not quoted verbatim, as the following illustrates:

(4) Mr. Graham has resolutely ducked the issue, saying he won't play the game of rumor-mongering, even though he has "learned from [his] mistakes."21

21 This is example (42) from Maier (2015), which he takes from The Chicago Manual of Style, 15th edition; Chicago: University of Chicago Press (2003). 
The mixed-quotation approach to FID is also endorsed in Cumming (this volume), while Stokke (this volume) extends it to related phenomena, including protagonist projection.

It would take us astray to scrutinize the arguments offered for and against the two approaches. What interests us here is how they can handle derogatory terms that occur in FID; and for this, the outlines that we have provided of the two approaches, however rough, will suffice.

\subsection{Back to pejoratives}

Let us now look back at the two examples of pejoratives in FID that we presented in Section 2.1. The mixed-quotation approach would analyze those as involving quotation, with certain elements unquoted, which would give us analyses along the following lines:

(Example 2, analyzed in terms of mixed-quotation)

After the anesthetic wore off, Tom made a deal with the patrol. "I'11 [he'd] get you your [them their] trophy, just not today", [he said]. "Have-[he had] too much money riding on this whale", (he thought). "Give [him] a week, and I'll [he'd] give their] prize", (he told them) "Patrols are [were] easy to bribe that way", (he thought), "It is [was] too bad, though, because I've [Tom'd] taken a real dislike to the asshole. Jake, on the other hand, seems[ed] like a pretty decent guy."

(Example 3, analyzed in terms of mixed-quotation)

Her chest tightened. She was resilient, often unflappable, used to things not going her way, practiced at gathering herself in trouble or after failure. "If he were to appear beside me [her] on this deck, $¥$ [she]'d slug him. The asshole", (she thought). "Who would make [her] laugh now?", (she wondered), "How could he have left [her] alone?" She considered the dark water churned into a white froth by the ship's passage.

The FID is seen here as a mixture of reported speech and thought in Example 2, and of thought and wondering in Example 3, which we have indicated with parentheses. Not much needs to be said about pejoratives per se; on this approach, they are simply expressions used in the (inner or outer) speech that is being reported.22

Let us now see how the two-context approach can handle pejoratives in FID. Here is a straightforward two-step answer. First, the two-context approach predicts that all speakeroriented expressions or constructions are anchored to the protagonist's rather than the narrator's

22 It may be worth noting, in Example 3, that the second occurrence of the protagonist's proper name, "Tom", occurs within FID, but reflects the narrator's rather than the protagonist's perspective. In the mixed-quotation approach, proper names can also be used to replace an unquoted first or second person pronoun. Maier (2015) notes that proper names in FID are sometimes interpreted from the protagonist's and sometimes from the narrator's perspective. 
point of view (Schlenker 2004, Eckardt 2012, 2015). Second, most accounts of expressives seem to agree on the idea that pejoratives are speaker-oriented. Together, the two claims predict that the derogatory content of pejoratives such as "asshole" in FID will be anchored to the context of the reported speech or thought, rather than the context of narration. Let us now briefly elaborate on the second claim.

In semantics, expressives were brought to attention in Kaplan (1999), an unpublished manuscript in which he discusses the pejorative "bastard" as well as expressive interjections such as "oops" and "ouch"; but it is not until Potts (2005) that pejoratives were given a full formal account. Roughly, Potts (2005) proposes to distinguish between a descriptive and an expressive dimension in meaning, the latter behaving in analogy with conventional implicatures. To illustrate the idea, suppose that Jake says:

(5) That asshole Tom made a deal with the patrol.

Potts' proposal is that the descriptive, truth-conditional meaning of (5) is simply that Tom made a deal with the patrol, but at the same time, (5) conventionally implicates that the speaker (Jake) has a negative attitude toward Tom. ${ }^{23}$ While Potts takes the derogatory content carried by a pejorative to be a conventional implicature, Macià $(2002,2014)$ and Schlenker $(2007)$ take it to be a presupposition. An utterance such as (5) is, in principle, subject to presupposition failure, just as any other sentence that contains a presupposition-trigger: if Jake has no negative attitude toward Tom, then (5) lacks a truth value. However, for Schlenker, presuppositions that are speaker-oriented and that furthermore concern the speaker's attitudes are "self-fulfilling", the idea being that when such a presupposition is triggered, it is automatically accommodated into the common ground (see Schlenker 2007: 241). Finally, Tonhauser et al. (2013) present a revisionary proposal that does away with the categories of presuppositions and conventional implicatures altogether, and offer a more fine-grained taxonomy of projective content.

\footnotetext{
23 The paraphrase of the conventional implicature carried by a pejorative will only be, at best, an approximation this is, in fact, what Potts (2007b) lists as one of the features of expressives, which he dubs descriptive ineffability: "Speakers are never fully satisfied when they paraphrase expressive content using descriptive, i.e., nonexpressive, terms" (2007b, 165). Also, the formal account in Potts (2007b) builds on Potts (2005) but does not tie the expressive dimension to conventional implicatures as tightly as Potts (2005) does.
} 
Nevertheless, they, too, agree with Potts, Macià and Schlenker on the idea that the derogatory content of pejoratives is speaker-oriented. ${ }^{24}$

To bring the point home, the differences between the existing accounts of pejoratives concern primarily the nature of the mechanism in virtue of which their derogatory content is projected. Relatedly, as pointed out in Section 2.1., those accounts are only concerned with the referential uses, as in example (5). However, a crucial point on which all these accounts agree is that the derogatory content is about the speaker's (negative) attitudes toward the referent, and in this respect, pejoratives fall within the broad scope of indexical expressions. When we pair any of these accounts with the assumption that when they occur in FID, indexicals get anchored to the protagonist's rather than the narrator's perspective - an assumption that lies at the very core of the two-context approach to FID -, we get the empirical predictions evidenced in Section 2.

\subsection{Back to slurs}

Several among the accounts of expressives discussed in the previous section are meant to apply not only to pejoratives but also to slurs. Schlenker (2007), in particular, submits the following lexical entry for the slur "honky". Let c be a context and w a possible world, and let \# indicate presupposition failure. Then:

(6) $[[$ honky] $](\mathrm{c})(\mathrm{w}) \neq \#$ iff the agent of c believes in the world of $\mathrm{c}$ that white people are despicable. If $\neq \#$, [[honky]] (c)(w) $=[[$ white $]]$ (c)(w). (Schlenker 2007: 237)

In other words, Schlenker's proposal is that, just like pejoratives, slurs such as "honky" trigger a presupposition about the attitude of the "agent" of a given context, that is, the speaker or thinker. The only difference between pejoratives and slurs is that a pejorative derogates only the person referred to, while a slur does so for the whole group to which the person belongs. If we combine an account such as Schlenker's with the two-context approach to FID, then the same two-step answer as discussed in the previous section will deliver the empirical predictions evidenced in Section 3.

Alas, matters are not that simple. For one thing, the vast philosophical literature on slurs casts doubt on the idea that slurs are (merely) speaker-oriented. The derogatory content carried by a slur goes beyond the attitudes of the speaker, involving the interlocutors in ways in which

\footnotetext{
${ }^{24}$ Marques and Garcia-Carpintero (2020) also defend a presuppositional account, the gist of which is, as they put is, that "pejoratives in general and slurs in particular trigger normative, non-propositional presuppositions that require speakers and hearers to share some specific reactive attitude" (p. 2). They clearly depart from Schlenker's contention that presuppositions triggered by pejoratives are self-fulfilling, and the speaker-oriented nature of pejoratives seems much more nuanced on their account. However, they present their account focusing on slurs, which is why we shall postpone its discussion to the next section.
} 
pejoratives do not. For another, even if slurs were speaker-oriented, some of the examples from Section 3, such as the one from Faulkner (1932), would still not be accounted for.

The aim of this section is to discuss certain difficulties that slurs, unlike pejoratives, raise. Those are tied to the highly offensive nature of slurs, and to the idea that their derogatory content can be quarantined only within quotation marks, if even that. Section 4.3.1. argues that if this idea is valid, then the mixed-quotation approach accounts better for slurs in FID than the two-context approach does. Section 4.3.2. shows that the idea may nevertheless be challenged, and discusses possible ways in which the two-context approach could account for the data from Section 3.

\subsubsection{Hyper-projectivity and complicity}

Slurs have been one of the most debated topics in philosophy of language in this century, and it is beyond the scope of this chapter to discuss the many problems that they raise and the possible solutions; for a survey, see e.g. Cepollaro (2020). There are two phenomena that we would like to touch upon here. The first is the observation that the derogatory content of a slur projects from any kind of embedding, even under speech- and attitude-reporting verb such as "says/thinks", which are known to behave as "plugs"; that is, which can block a presupposition from projecting. The second, already mentioned, is the observation that the derogatory content of a slur does not simply concern the attitudes of the speaker, but also of the hearer, and even by-standers. The two observations together make it difficult to see how the behavior of slurs in FID can be explained by the two-context approach, and appear to yield support to the mixed-quotation approach.

Here is how Elisabeth Camp formulates the first observation, presenting it as a problem for presuppositional theories of slurs:

The problem is that the [derogating] perspective [associated with a slur] appears to be 'hyper-projective': it also typically projects across indirect attitude and speech reports, which are supposed to be projection "plugs." Thus, utterances like " $\{$ Bridget thinks/says that //According to Bridget\} spics can't keep their hands to themselves" implicate the reporting speaker, and not just Bridget, in the derogation of Latinos. Projection across attitude reports is not universal (...) but 'quarantining' is significantly more difficult and less common with slurs than with standard presuppositions, in a way that calls for explanation. (Camp 2018)

Let us leave aside the question whether this is a devastating problem for presuppositional theories of slurs, to see how this affects the applicability of the two-context approach to the cases discussed in Section 3. As noted earlier, the two-context approach stresses the similarities between FID and ID, as is particularly clear in Sharvit's proposal, since she posits covert operators that shift the interpretation of certain expressions to the protagonist's context. True 
enough, those operators are different from the standard speech and attitude reporting verbs, given that the interpretation of indexicals such as "tomorrow" is sensitive to the former but not to the latter: an utterance like "Bridget thought/said that it would rain tomorrow" is about the day after the report takes place, not the day after the reported thought or speech took place. But the twocontext approach tells us that when an expression whose interpretation normally does not shift under speech and attitude verbs gets anchored to the protagonist's context in FID, then this is because the expression at stake is indexical, or speaker-oriented. The two-context approach can, then, handle the hyper-projectivity of slurs in a straightforward way if it can show that slurs, too, are indexical.

The latter, however, is a problematic assumption. There is a remarkable difference between utterances that explicitly express the speaker's negative attitudes toward a group and those that contain slurs. Compare:

(7) Some French people live next door to us, and I deeply dislike the French / I have hatred and contempt toward the French / I think that French people are despicable.

(8) Some Frogs live next door to us.

From both (7) and (8), one can infer that the speaker has a derogatory attitude toward French people. However, while the speaker of (7) self-ascribes this attitude, an utterance such as (8) displays it in such a way that the hearer, and even by-standers, appear to fall prey to it. A hearer who fails to respond to (7) does not ipso facto endorse the speaker's derogatory attitude, while a hearer who lets (8) go by seems to derogate French people to almost equal extent as the speaker. This feature of slurs is known as "complicity". As Croom puts it, "just hearing [the N-word] can leave one feeling as if they have been made complicit in a morally atrocious act" (2011: 343 ); or, as Camp puts it, "slurs make recalcitrant hearers feel complicit in the speaker's way of thinking" (2013: 333; for discussion, see also Jeshion 2013, 2018; Cepollaro 2020; Camp 2018). Anderson and Lepore further point out that even when a slur is not used but only mentioned or quoted, "bystanders (even when silent) are uncomfortable, often embarrassed, when confronted by [it]. Whatever offenses these confrontations exact, the audience risks complicity, as if the offense were thrust upon them" (2013: 27).

To bring the point home, the difficulty for the two-context approach to account for the examples from Section 3 is that there is no account of slurs on which it can immediately build so as to yield the right empirical predictions. In particular, the strategy to which it could appeal in order to handle pejoratives in FID does not seem to be available for slurs. For one thing, given that the derogatory content that slurs carry is hyper-projective, it typically scopes out of the operators that otherwise block projection from other presupposition-triggers. To be sure, indexicals such as 
"tomorrow" also scope out of those, hence the two-context approach could still predict that slurs get anchored to the protagonist's context, if only it could show that slurs, too, are indexicals. This assumption, however, is highly problematic. The derogatory content is not simply speakeroriented; it engages the audience as well. Furthermore, as we saw in section 3.1., it often happens that slurs in fictional narratives fail to be perceived as merely reflecting the narrator's point of view; instead, they often manage to engage the writer as well.

In the next section, we will examine other possible strategies, but for the time being, let us note that, prima facie at least, the mixed-quotation approach appears to have advantage over the twocontext approach. The reason is that if there is any mechanism that can "quarantine" the derogatory content of a slur, then it is quotation. This allows the mixed-quotation approach to explain why the derogatory content of those occurrences of slurs in FID that we presented in Section 3 does not engage the narrator, let alone the writer, but only reflect the protagonist's perspective.

\subsubsection{A second attempt}

With the literature on slurs becoming ever more sophisticated and specialized, it is impossible to examine in this chapter whether and which other accounts of slurs could be paired with the twocontext approach to FID so as to deliver the right empirical predictions. The goal of this section is to gesture toward one such direction.

Let us start by noting that the hyper-projectivity of slurs is a tendency, rather than an unbreakable rule. Here are some examples of slurs, offered by various authors in the literature, for which it has been claimed (although not without controversy) that the derogatory content fails to project:

(9) Racists believe that Chinese people are chinks. (Hom 2008)

(10) My father screamed that he would never allow me to marry that kraut Webster. (Kratzer 1999)

(11) I am not prejudiced against Caucasians. But John, who is, thinks/claims that you are the worst honky he knows. (Schlenker 2003, 2007)

As it happens often in philosophy and semantics, it is difficult to rely on one's intuitions. While examples such as these appear convincing to some people, they fall short of convincing others. For instance, in discussing Schlenker's example in (11), Anderson and Lepore, providing further examples, contend that "employing slurs in indirect report complements is an ineffective means to capturing an original slur by whoever is being reported: whatever offense the report commits is endorsed only by the reporter" (2013, p. 30). 
Luckily, when intuitions fail us, we can resort to empirical evidence. For one, there is a growing body of experimental data concerning speakers' intuitions about the offensiveness of slurs. For another, there are corpus-drawn examples. Let us discuss them in this order.

Among experimental studies, the most relevant to our present concerns is Cepollaro, Sulpizio and Bianchi (2019). ${ }^{25}$ They tested speakers' intuitions on the offensiveness of slurs (as well as insults) in Italian, and compared them across various conditions. In particular, they ran a threelevel comparison between slurs in isolation (that is, mere lists of words), slurs in atomic predications (that is, sentences of the form $X$ is $a$-slur-), and slurs in ID (that is, sentences of the form $Y$ said that $X$ is a -slur-). Their study has shown that the perceived offensiveness of slurs diminishes significantly when they occur in ID. To be precise, the study does not show that the derogatory content fails to project in ID, given that ID reports that contain slurs are still perceived as offensive. Nevertheless, since they are perceived as less offensive than atomic predications, embedding a slur in a speech report must have some impact on its derogatory content.

Turning to corpus-drawn examples of slurs in narratives, recall that Example 8 from section 3.2., copied below, could be considered with equal ease as a case of FID as of ID. In addition, among the very few not-quoted occurrences of the N-word in Faulkner's Light in August, one, provided below, occurs in ID.

(Example 8, repeated)

(...) And when his boss said that Art shouldn't take what he said personally, in fact he knew Art was not a Jap, but a chink, plus he had called someone else a lazy wop just that morning, it was just his style, Art said again that he understood. (Jen 1994, p. 17)

(Example 9)

They heard how one night a party of carelessly masked men went to the minister's house and ordered him to fire her. Then they heard how the next day the woman told that she quit herself because her employer asked her to do something which she said was against God and nature. And it was said that some masked men had scared her into quitting because she was what is known as a high brown and it was known that there were two or three men in the town who would object to her doing whatever it was which she considered contrary to God and nature, since, as some of the younger men said, if a nigger woman considered it against God and nature, it must be pretty bad. (Faulkner 1932, p. 31)

\footnotetext{
25 Other studies include e.g. O'Dea and Saucier (2017) and Bianchi et al. (2019), both of which are concerned with certain general aspects regarding the offensiveness of slurs, rather than the question whether offensiveness diminishes under certain conditions.
} 
If there are cases, as the above suggest, in which the derogatory content of a slur is not anchored to the speaker's perspective, yet the slur does not occur in a quotational construction, then the prospects of the two-context approach to FID are more encouraging than the previous section made it seem. It still remains to decide to which aspects of the context the semantics of slurs is sensitive. We have seen that accounts such as Schlenker's, which analyze slurs in terms of presuppositions that are about the speaker's derogatory attitudes toward the target group, are not without problems. However, if the semantic clause for slurs is modified in such a way that it concerns not only the attitude of the speaker alone, but, say, of the community to which the speaker belongs, then it becomes easier to handle the phenomenon of complicity. The presuppositional account in Macià (2014) takes a step in that direction by proposing the following lexical entry for "chink":

(12) $[[$ chink $]](\mathrm{C}, \mathrm{w})(\mathrm{a})=$

True if in $\mathrm{C}$ speakers are disposed to treat Chinese people with a certain kind of contempt because they are Chinese, and a is Chinese;

False if in $\mathrm{C}$ speakers are disposed to treat Chinese people with a certain kind of contempt because they are Chinese, and a is not Chinese;

nothing, otherwise. (Macià 2014: 4)

Unfortunately, Macià is not explicit on how the bare plural "speakers" should be interpreted. Nevertheless, the contrast with the definite description "the speaker" that he uses for the lexical entries of certain other expressions, such as pejoratives, suggests that he takes the derogatory attitudes toward the target group to be shared among the discourse participants.

Another presuppositional account of slurs that does not make them speaker-oriented - in fact, even less so than Macià's - is presented in Cepollaro and Stojanovic (2016) and further developed in Cepollaro (2020). The main idea is that the presupposition triggered by a slur is not about anyone's derogatory attitudes; rather, it is a generic evaluative proposition concerning the target group. Although the cited references do not spell out formally the lexical entries for slurs, the informal gloss in Cepollaro and Stojanovic (2016) can be made to fit the template in (12) as follows: 26

(13) $[[$ frog $]](C, w)(a)=$

True if $[[\mathrm{bad}]](\mathrm{C}, \mathrm{w})(\mathrm{a})=$ True, and a is French;

False if $[[\mathrm{bad}]](\mathrm{C}, \mathrm{w})(\mathrm{a})=$ True, and a is not French;

nothing, otherwise.

\footnotetext{
26 Alternatively, it could be made to fit the template used by Schlenker, as in (6). Cepollaro (p.c.) suggested the following lexical entry: [[frog] $(\mathrm{c})(\mathrm{w}) \neq \#$ iff in the world of c French people are despicable for being French. If $[[\operatorname{frog}]](\mathrm{c})(\mathrm{w}) \neq \#$ then $[[\mathrm{frog}]](\mathrm{c})(\mathrm{w})=[[$ French $]](\mathrm{c})(\mathrm{w})$.
} 
What the proposal precisely amounts to will depend on the semantics supplied for the evaluative term "bad". An informal gloss of the clause in (13) is that using the slur "frog" for someone is tantamount to using the predicate "French", but also presupposing that the person at stake is bad. For instance, the sentence in (8) would state that there are French people living next door, and presuppose that those people are bad. The trick is to recognize that the evaluative term "bad" is highly context-sensitive. In particular, a person can be bad in some respects but not in others (see Stojanovic 2016). The hidden parameter in-such-and-such-respect is what leaves room for further information that is typically conveyed by a slur, such as the idea that a person is bad in terms of their race, nationality, or other social category. The semantics itself does not capture all the features attributed to slurs, like the idea that by using a slur, derogatory attitudes toward the whole group, and not only the person referred to, are conveyed and expected to be endorsed by one's interlocutors. Rather, the semantics encodes only a thin negative evaluation, and the rest is derived by putting together the semantics, the way presuppositions work in general, as well as further pragmatic and metasemantic factors (see Cepollaro and Stojanovic 2016 for details).

To see how these approaches to slurs may combine with the two-context approach to FID, let us look back at the relevant passage from Example 5:

(14) To Maycomb, Tom's death was typical. Typical of a nigger to cut and run. Typical of a nigger's mentality to have no plan, no thought for the future, just run blind first chance he saw.

FID, together with the perspectival expression "to Maycomb", introduces a context distinct from the one in which the narration takes place. Let $\theta$ stand for the former and $v$ for the latter. While the past tense in "was" and "saw" is interpreted relative to $v$, the presupposition triggered by the $\mathrm{N}$-word is interpreted relative to $\theta$. If we go with Macià's proposal, then the presupposition that speakers are disposed to treat Black Americans with a certain kind of contempt is resolved in the context set in Alabama in the 1930s, in which the narrated events took place. This explains how the discourse can remain felicitous, even if the context $v$ itself, in which the narration takes place, is not a racist one, and the narrator herself is not disposed to treat them with any kind of contempt. If we go instead with Cepollaro and Stojanovic's proposal, then again, the past tense is resolved from the narrator's perspective, but the presupposition that Black Americans are bad (in some relevant respect) is anchored to $\theta$, that is, to the context of the racist Alabama of the 1930s.

Let us close by briefly pointing to yet another promising direction: the presuppositional account of slurs in Marques and García Carpintero (2020). Their proposal is cast within a broadly Stalnakerian conception of contexts, according to which contexts are best analyzed as sets of attitudes that are shared among the conversation participants. However, they point out that in order to account for phenomena related to derogatory language, contexts must not be limited to 
doxastic attitudes; they propose to include emotional reactive attitudes as well. Among those, negative attitudes such as resentment and contempt are most relevant to accounting for slurs. The proposal, in a nutshell, is that just as the ordinary presupposition triggers require that the relevant proposition be among the beliefs shared among the conversation participants, a slurs requires that the relevant negative attitude be similarly shared. This manoeuvre helps in accounting for complicity (since a slur will be licensed only if the conversation participants share the relevant negative attitude toward the target group) as well as for hyper-projectivity (since the usual operators operate on doxastic rather than reactive attitudes). For this account to be applicable to slurs in FID, the two-context approach needs to be suitably amended. Both the context of narration and the context of reported speech or thought now need to be analyzed as comprising a set of relevant reactive attitudes. Such an amendment might well turn out to be further motivated by other constructions that appear in FID (possibly exclamatives). How exactly the combination of such a two-context approach to FID and Marques and García Carpintero (2020)'s approach to is to be spelled out falls beyond the scope of the present chapter.

In conclusion, both pejoratives and slurs in FID raise interesting novel issues for the study of the language of fiction. The two main approaches to FID, namely, the two-context approach and the mixed-quotation approach, appear both capable of handling the cases presented and discussed. Nevertheless, the choice between them may end up imposing certain constraints on the choice of an underlying account of derogatory terms themselves. Here, we have barely touched upon some of the problems that pejoratives and slurs in FID raise for some of those accounts. What we hope to have achieved, though, is set the premises for a new research agenda that brings together the study of narrative and the philosophy of $(\mathrm{bad})$ language.

\section{Acknowledgments}

I would like to thank Emar Maier and Andreas Stokke for the invitation to contribute to this volume, as well as for their constructive comments on a previous draft. I am very grateful to the audiences at the workshop The Language of Fiction in Uppsala (July 2019), at the 3rd Workshop on the Foundations and Methods in Natural Language Semantics in Barcelona (November 2019), and at the 10th European Congress of Analytic Philosophy (August 2020), for feedback and discussion. I acknowledge institutional support from the project ANR-17-EURE-0017 FrontCog.

\section{References}

Abrusán, Márta (2020). "The Spectrum of Perspective Shift: Free Indirect Discourse vs. Protagonist Projection", Linguistics and Philosophy. https://doi.org/10.1007/s10988-020-09300-z Abrusán, Márta (this volume) "Computing Perspective Shift in Narrative". 
Amaral, Patricia, Craige Roberts and Elisabeth Allyn Smith (2007). "Review of The Logic of Conventional Implicatures by Chris Potts", Linguistics and Philosophy 30 (6): 707-749.

Anderson, Luvell, Haslanger, Sally and Langton, Rae (2012), "Language and Race", in Fara, Delia and Russell, Gillian (eds.), Routledge Companion to the Philosophy of Language, London, Routledge, 753-767

Anderson, Luvell and Lepore, Ernie (2013). "Slurring words", Nô̂s, 47 (1): 25-48.

Ashwell, Lauren (2016). "Gendered slurs", Social Theory and Practice, 42 (2): 228-239

Banfield, Ann (1973). "Narrative style and the grammar of direct and indirect speech", Foundations of Language 10(1): 1-39.

Banfield, Ann (1982). Unspeakable Sentences: Narration and Representation in the Language of Fiction. London: Routledge.

Barwise, Jon and Perry, John (1983). Situations and Attitudes. Cambridge: MIT Press.

Bianchi, Mauro et al. (2019). "On the Descriptive and Expressive Function of Derogatory Group Labels: An Experimental Test", Journal of Language and Social Psychology 38: 756-772.

Bimpikou, Sofia (2020). "Who Perceives? Who Thinks? Anchoring Free Reports of Perception and Thought in Narratives", Open Library of Humanities 6 (2): 1-38. DOI: https://doi.org/ 10.16995/olh.484

Bolinger, Renée (2017). "The pragmatics of slurs", Nô̂s, 51 (3): 439-462.

Camp, Elisabeth (2013). "Slurring perspectives", Analytic Philosophy 54 (3): 330-349.

Camp, Elisabeth (2018). "A dual act analysis of slur", in Sosa, David (ed), Bad Words:

Philosophical Perspectives on Slurs, Oxford: OUP.

Cepollaro, Bianca (2015). "In defense of a presuppositional account of slurs", Language Sciences 52: 36-45.

Cepollaro, Bianca (2017). "Slurs as the shortcut of discrimination", Rivista di estetica 64: 53-65.

Cepollaro, Bianca (2020). Slurs and Thick Terms: When Language Encodes Values. Lanham, Maryland: Rowman \& Littlefield.

Cepollaro, Bianca, Filippo Domaneschi and Isidora Stojanovic (2020). "When is it ok to call someone a jerk? An experimental investigation of expressives", Synthese. https://doi.org/ $10.1007 / \mathrm{s} 11229-020-02633-\mathrm{z}$

Cepollaro, Bianca and Stojanovic, Isidora (2016). "Hybrid evaluatives: in defense of a presuppositional account", Grazer Philosophische Studien 93 (3):458-488. 
Cepollaro, Bianca, Simone Sulpizio and Claudia Bianchi (2019). "How bad is it to report a slur? An empirical investigation", Journal of Pragmatics 146: 32-42.

Croom, Adam (2011). "Slurs", Language Sciences 33: 343-358.

Cumming, Sam (this volume) "Narrative and Point of View".

Deal, Amy Rose (2017). "Shifty asymmetries: universals and variation in shifty indexicality." Unpublished manuscript. UC Berkeley. http://linguistics.berkeley.edu/ ardeal/papers/Dealindexicals-2017.pdf

Diaz-Legaspe, Justina (2019). "What is a slur?", Philosophical Studies. DOI: 10.1007/s11098019-01259-3

Doron, Edit (1991). "Point of view as a factor of content", in Moore, S., Wyner, A.Z. (eds.): Proceedings of SALT 1. NY, Cornell University: 51- 64.

Eckardt, Regine (2012). "Particles as speaker indexicals in free indirect discourse", inHogeweg, Lotte and Elin McCready (eds.), Particles. Special issue of Sprache und Datenverarbeitung, 99 119.

Eckardt, Regine (2015). The Semantics of Free Indirect Discourse: How Texts Allow Us to Mindread and Eavesdrop. Brill, Leiden/Boston.

Genette, Gérard (1972). Discours du récit. Editions Seuil. English translation by Jane E. Lewin, Narrative Discourse. Cornell University Press 1980.

Harris, Jesse and Potts, Christopher (2009). "Perspective-shifting with appositives and expressives", Linguistics \& Philosophy 32: 523-552.

Hinterwimmer, Stefan (2017). "Two kinds of perspective taking in narrative texts", Proceedings of SALT 27: 282-301.

Hom, Christopher (2008). "The semantics of racial epithets", The Journal of Philosophy, 105 (8): 416-440.

Jeshion, Robin (2013). "Expressivism and the offensiveness of slurs", Philosophical Perspectives, 27 (1): 231-259.

Jeshion, Robin (2018). "Slurs, dehumanization, and the expression of contempt", in Sosa, David (ed.), Bad Words, Oxford: OUP.

Kaiser, Elsi (2015). "Perspective-shifting and free indirect discourse", Proceedings of SALT 25: 346-372.

Kaplan, David (1989), "Demonstratives", in Joseph Almog, John Perry \& Howard Wettstein (eds.), Themes from Kaplan, New York: Oxford University Press, 481-614. 
Kaplan, David (1999). "The meaning of 'ouch' and 'oops': explorations in the theory of meaning as use. Unpublished manuscript.

Kratzer, Angelika (1999). "Beyond ouch and oops", Handout for the Cornell Conference on Theories of Context Dependency. https://semanticsarchive.net/Archive/WEwNGUyO/

Macià, Josep (2002). "Presuposición y significado expressivo", Theoria: Revista de Teoria, Historia y Fundamentos de la Ciencia 3 (45): 499-513.

Macià, Josep (2014). "Expressive meaning and presupposition", Handout for the Conference "Names, Demonstratives, and Expressives", Gargnano, Italy.

Maier, Emar (2015). "Quotation and unquotation in free indirect discourse", Mind \& Language 30: $345-373$.

Maier, Emar (2016). "A plea against monsters", Grazer Philosophische Studien 93 (3): 363-395.

Marques, Teresa and Manolo García Carpintero (2020). "Really expressive presuppositions and how to block them", Grazer Philosophische Studien 93 (1): 138-158.

Nunberg, Geoffrey (2018). "The social life of slurs", in Daniel Fogal, Daniel Harris \& Matt Moss (eds.), New Work on Speech Acts. Oxford University Press.

O'Dea, Conor and Donald Saucier (2017). "Negative emotions versus target descriptions:

Examining perceptions of racial slurs as expressive and descriptive", Group Processes and Intergroup Relations 20 (6): 813-830.

Potts, Christopher (2005). The logic of conventional implicatures, Oxford: OUP.

Potts, Christopher (2007a). "The dimensions of quotation", in Chris Barker \& Pauline Jacobson (eds.), Direct compositionality, New York: Oxford University Press, 405-431.

Potts, Christopher (2007b). "The expressive dimension", Theoretical Linguistics 33 (2): 165198.

Potts, Christopher and Harris, Jesse A. (2009). Embedded appositives (annotated data). http:// christopherpotts.net/ling/data/embeddedappositives/

Schlenker, Philippe (2003). "A plea for monsters", Linguistics and Philosophy 26: 29-120.

Schlenker, Philippe (2004). "Context of thought and context of utterance (a note on free indirect discourse and the historical present)", Mind and Language 19(3). 279-304.

Schlenker, Philippe (2007). "Expressive presuppositions", Theoretical Linguistics 33: 237-245.

Sennet, Adam and Copp, David (2019). "Pejorative verbs and the prospects for a unified theory of slurs", Analytic Philosophy: 1-22. 
Shan, Chung-chieh (2007). "Causal reference and inverse scope as mixed quotation", in Maria Aloni, Paul Dekker and Floris Roelofsen (eds.), Proceedings of the Amsterdam Colloquium, Amsterdam: ILLC.

Shan, Chung-chieh (2011). "The character of quotation", Linguistics and Philosophy 33: 417443.

Sharvit, Yael (2008). "The puzzle of free indirect discourse", Linguistics and Philosophy 31: 353-395.

Simons, Mandy, Tonhauser, Judith, Beaver, David, and Roberts, Craige (2010). "What projects and why", Proceedings of SALT 20: 309-327.

Sloane, David (2014). "The N-word in Adventures of Huckleberry Finn reconsidered", The Mark Twain Annual 12 (1): 70-82.

Stokke, Andreas (2013). "Protagonist Projection", Mind and Language 28 (2): 204-232.

Stokke, Andreas (this volume). "Protagonist Projection, Character Focus, and Mixed Quotation".

Stojanovic, Isidora (2016). "Evaluative Predicates and Evaluative Uses of Ordinary Predicates", in Bekki, Daisuke et al. (Eds.) New Frontiers in Artificial Intelligence: JSAI-isAI 2015

Workshops, Revised Selected Papers, Lecture Notes in Computer Science. Springer-Verlag, 128-140.

Stojanovic, Isidora (2020). "Indexicality: I, Here, Now", in Matthewson, Lisa, Cecile Meier, Hotze Rullmann, Thomas E. Zimmerman, and Daniel Gutzmann (Eds.), The Wiley Blackwell Companion to Semantics, Wiley's. https://doi: 10.1002/9781118788516.sem123

Tonhauser, Judith, Beaver, David, Roberts, Craige and Simons, Mandy (2013). "Toward a taxonomy of projective content", Language 89 (1): 66-109.

\section{Resource texts}

Faulkner, William (1932). Light In August. New York: Vintage Books. Vintage International Edition, October 1990.

Jen, Gish (1994). "Birthmates", Plougshares 20 (4): 81-98.

Johnson, Greg (1996). "The Chinese Box", Chicago Review 42 (2): 1-13.

Lee, Harper (1960). To Kill a Mockingbird. McIntosh and Otis, Inc.

Lee, Kathleen (2015). All Things Tending Toward the Eternal. Evanston: TriQuarterly Books. Markeley, Stephen (2017). "On the Phase Transitions of Methane Hydrates", Iowa Review 46 (1): 158-172.

Vladimirsky, Leo (2014). "Collar", Fantasy and Science Fiction 126 (8/4): 5-18. Zola, Émile (1885). Germinal. 